\title{
A PRÁTICA DOCENTE NO PROCESSO DE IDENTIFICAÇÃO DO ABUSO SEXUAL INFANTIL
}

\author{
THAÍS MORATORI CASTELANI* \\ DENISE D'AURIA TARDELI**
}

\begin{abstract}
RESUMO
Este trabalho tem por objetivo apontar a importância de considerar a sexualidade como uma das partes fundamentais do desenvolvimento integral da criança. Indica qual deve ser o papel da instituição de ensino e do professor enquanto possíveis agentes mediadores e modificadores, frente à comunidade escolar para prevenir futuros abusos, denunciando casos suspeitos e acolhendo o aluno que sofre ou sofreu abusos sexuais. Ao pensar no desenvolvimento integral da criança, colocando-a como centro de seu ensino- aprendizagem, diversos fatores são considerados para que essa experiência dentro do ambiente escolar seja vivida plenamente. Contudo, passa a existir uma lacuna no desenvolvimento infantil quando um dos processos é descartado pela instituição escolar, sendo negligenciado pela falta de diálogo e de ações diante da descoberta do próprio corpo pela criança. Para compreender a necessidade da discussão sobre o desenvolvimento da criança e a sexualidade infantil, foram utilizadas as teorias de dois autores- referência na psicologia da educação e psicanálise: Jean Piaget e Sigmund Freud. Mesclando as duas teorias e as informações trazidas pela autora Christiane Sanderson, que discute a questão do abuso sexual infantil, foi possível definir como e qual
\end{abstract}

\footnotetext{
* Aluna concluinte do curso de Pedagogia da Universidade Metodista de São Paulo.

** Orientadora do Trabalho de Conclusão de Curso de Pedagogia, do qual resultou este artigo.
} 
é o papel do professor e da instituição escolar desde o momento de identificação, até a denúncia do abuso. O método utilizado para esta pesquisa foi de natureza qualitativa, adotando-se como metodologia a pesquisa bibliográfica de cunho exploratório.

Palavras-chave: Abuso Sexual. Infância. Prática Docente.

\begin{abstract}
This study aims to show the importance of considering sexuality as one of the fundamental parts of the integral development of a child. Indicating the role a teacher and the educational institution must play as possible mediators agents and modifiers in front of the school community to prevent future abuses, uncovering suspicious cases, and embracing students that are or have been sexually abused. When thinking about the full development of a child, placing them in the center of its teaching-learning complex, a myriad of factors are considered so as to achieve a wholly lived experience within school environment. However, a loophole appears during the childhood development when one of the processes is dismissed by the schooling institution, neglected by the lack of dialogue and action about body discovering. In order to comprehend the need for discussion on childhood development and children's sexualities, theories of Jean Piaget and Sigmund Freud- well-acknowledged in educational psychology field and psychoanalysis- were applied in this study. Merging two theories and information brought by the author Cristiane Sanderson, that discusses child sex abuse, it was able to define what role the teacher and the school play from the moment of discovering the abuse until its report.The method used for this research was of qualitative nature, adopting as methdology a bibliographical research with explorative hallmark.
\end{abstract}

Keywords: Sexual Abuse. Childhood. Teaching Practice. 


\section{INTRODUÇÃO}

Pensar e repensar a prática docente não é uma tarefa fácil, não é possível avaliar um professor sem antes vê-lo dentro da sala aula; tampouco compreender a existência de uma prática efetiva sem embasamento teórico, capaz de fazer o profissional da educação refletir constantemente a aplicabilidade do seu saber, qual seu papel social e a importância de uma educação acessível, inclusiva e reflexiva. Surge, portanto, a necessidade de pensar qual o impacto da ação docente dentro de sala de aula e de que modo essa prática interfere, positiva ou negativamente, no processo de desenvolvimento das competências e habilidades adquiridas ao longo da infância, para que a criança atinja seu desenvolvimento integral.

Um fator determinante para a dinâmica dentro da sala de aula é a relação que o professor tem com a prática docente. Se o professor se enxerga e age de acordo com a abordagem construtivista, que assume o papel de mediador dentro da sala, que considera os saberes prévios dos alunos e compreende que a criança é um ser social e que os acontecimentos à sua volta influenciam na construção do sujeito e no modo que existe no mundo, sua prática respeitará as etapas do desenvolvimento e da individualidade da criança.

Mas, se dentro do ambiente escolar o professor assume uma postura de detentor do saber, atendo-se apenas à transmissão do conteúdo programático, desconsiderando a singularidade de cada aluno, enxergando a criança como um depósito de informações que deve apenas memorizar o que é transmitido, sua prática será permeada de autoritarismo, reforçando atitudes de obediência, repudiando e punindo comportamentos questionadores e inadequados, segundo a abordagem tradicional.

No presente trabalho, a distinção das duas abordagens dentro da sala de aula é um dos pontos cruciais para entender a relação da prática docente e do desenvolvimento infantil. Ao compreender que o desenvolvimento integral da criança é 
composto por fases e competências que são atingidas quando estimuladas, de forma que o aluno seja protagonista do seu próprio aprendizado, o professor consegue atribuir à sua prática objetivos claros, que instiguem a interação sujeito-objeto. Assim sendo, apresenta oposição à prática tradicional, que segue a linha do reforço positivo ou negativo, sustentada pelo behaviorismo.

Para tanto, o artigo presente aborda, de início, quais são as fases do desenvolvimento infantil segundo a teoria de Jean Piaget, que é complementada com a teoria de Sigmund Freud sobre a percepção e desenvolvimento da sexualidade na infância. $\mathrm{Na}$ segunda parte, são apresentados dados estatísticos sobre a violência sexual no Brasil e quais são os efeitos colaterais que esses abusos geram nas vítimas. A terceira, e última parte, levanta a discussão acerca do papel docente dentro da instituição de ensino e como a abordagem escolhida para direcionar a prática docente interfere nas questões referentes à violência sexual, tanto no processo de identificação, quanto no acolhimento das vítimas.

\section{INFÂNCIA E SEXUALIDADE: DESENVOLVIMENTO NEGADO}

A construção do sujeito passa a existir a partir do seu nascimento. É no primeiro contato com o mundo que diversas informações começam a ser absorvidas pelos bebês. São informações que estimulam os sentidos, que advêm do simples contanto com o ambiente, mas que causam um grande impacto no seu processo de desenvolvimento integral. Além dos fatores sensoriais, o meio sociocultural no qual a criança se insere é outro ponto determinante na descoberta e construção do indivíduo, sendo responsável pela maneira que os estímulos cognitivos, afetivos e também morais serão trabalhados para que a criança alcance a sua integralidade.

O desenvolvimento integral da criança é gradativo e acontece de acordo com a faixa etária em que ela se encontra; em cada fase ela adquire novas competências, que são modalidades estruturais da inteligência; são divididas em competências cogni- 
tivas, emocionais, motoras, sociais, culturais, simbólicas e morais. É a partir da estruturação de cada competência que a relação com o mundo exterior começa a existir e a estimular seu agente a atingir seu objetivo, seja ele um objeto, sensação, pessoa ou qualquer nova ação que desperte o seu interesse. A partir dessas competências e do desejo imediato do saber fazer, a criança desenvolve habilidades, que, ao serem aperfeiçoadas, tornam-se competências que atingem um novo patamar, de acordo com a maturação neurológica e fisiológica do indivíduo.

Seguindo a ordem cronológica do desenvolvimento da criança, segundo a teoria de Jean Piaget, a competência motora é a primeira a ser trabalhada; é a partir dela que a criança construirá um esquema de lógica de suas ações e percepções. É manifestada ainda nas primeiras horas de vida com os reflexos apresentados pelo bebê, na hora da amamentação, e, por exemplo, quando ele faz o movimento de sucção e deglutição. O cognitivo será trabalhado junto com a competência sensório motora, responsável por despertar a consciência do próprio corpo, e a partir dela a criança conseguirá se diferenciar de outros elementos físicos no ambiente.

A influência do mundo exterior e da cultura começa a aparecer, com maior clareza, no período pré-operatório, indo dos 2 aos 7 anos, quando a competência simbólica começa a ser trabalhada. A partir dela a criança expressa sua percepção de mundo e das suas vivências, utilizando instrumentos concretos e signos culturais, como a linguagem, internalizados para essa comunicação. Passa a desenvolver, também, o pensamento verbal - a fase dos porquês - e a intuição.

Dos 7 aos 12 anos a criança entra no processo operatório-concreto; é a partir desta fase que ela sai do seu pensamento egocêntrico, erroneamente confundido com egoísmo, e começa a descentralizar o discurso focado no "eu". Utiliza do pensamento lógico sobre as coisas concretas, tendo noção de relação entre os objetos, sua classificação e separação. 
O desenvolvimento moral acontece de acordo com a faixa etária e maturação, pois diz respeito às regras e como a criança compreende sua aplicabilidade, ou seja, para que servem e de que maneira são organizadas ou reorganizadas, dentro de um espaço ou situação coletiva. Piaget (1967) utiliza desta competência para pensar os deveres morais que existem dentro da sociedade, considerando que a interpretação e obediência a essas regras e deveres serão cumpridas de acordo com cada etapa do processo de desenvolvimento e vivência da criança.

Dada as fases do desenvolvimento infantil e a importância dos estímulos do ambiente e a sua influência para o pleno desenvolvimento da criança, entra em discussão a questão da sexualidade infantil. Não há uma "competência sexual" para ser desenvolvida diretamente; porém, ao pontuar as demais competências e compreender como cada uma delas funciona e precisa ser estimulada para contemplar sua integralidade, é possível distinguir as características que também aparecem em seu desenvolvimento sexual.

Para começar a trabalhar pontos relacionados à sexualidade infantil, é necessário compreender que, ao contrário do que se acredita popularmente, o estímulo e a manifestação de prazer sexual da criança acontecem de uma forma diferente dos estímulos sexuais da vida adulta. $\mathrm{O}$ adulto busca o ato sexual para o prazer orgástico ou reprodutivo, com foco nos genitais. A criança, por sua vez, segundo as teorias de Sigmund Freud, tem como estímulo sexual tudo aquilo que lhe gera um prazer não orgástico ou libidinoso. O ato da amamentação, por exemplo, é um ato de extremo prazer para o bebê e é experimentado logo nas primeiras horas de vida. Ele desfruta do prazer do movimento de sucção, experimenta a sensação de saciedade e de contato corporal, estimulando sua competência sensório-motora, não havendo nesse ato qualquer resquício de perversão.

A autora Maria Cristina Kupfer (1997, p.40), em seu livro Frend e a educação: mestre do impossivel, pontua que as perversões 
sexuais que se manifestam na vida adulta são resultados da permanência de uma das pulsões não trabalhadas na infância. As perversões são divididas por Freud em três partes e são chamadas de pulsões parciais, sendo respectivamente: a pulsão oral, já citada no caso da amamentação, mas que se manifesta também quando o bebê suga os dedos das mãos ou dos pés. A pulsão anal é a segunda, está associada ao controle dos esfíncteres, pois ao defecar experimenta outro tipo de prazer. A última pulsão é a escópica e é atribuído a ela o prazer que a criança sente em olhar o mundo ao seu redor.

As pulsões proporcionam os momentos de autodescoberta do corpo da criança, em que é a partir delas que a criança descobrirá a sensação de prazer e satisfação. Para Maria Cecília Cortez Christiano de Souza ${ }^{1}$ :

[...] a sexualidade nasce paralelamente a uma atividade vital, como se fosse um benefício de prazer marginal obtido graças a essa mesma satisfação. A sexualidade nasce, portanto, apoiada numa função biológica, e a característica de apoio ou analítica, fornece a pista fundamental de sexualidade [...]. (1997, p. 17).

Alinhando a teoria de Freud com a de Piaget, é inquestionável a importância da descoberta do próprio corpo na infância; o estímulo refletirá diretamente na fase adulta, tanto positiva quanto negativamente. Como já apontado, não há uma competência sexual que precise ser diretamente trabalhada para ser desenvolvida; ela está atrelada às outras fases do desenvolvimento da criança. A competência sensório-motora, por exemplo, demonstra a importância de a criança descobrir o mundo, mas também a si mesma, pois a partir da descoberta do prazer ela será capaz de experienciar outras situações que desenvolvam outras habilidades, de mesmo modo, quando conhecer a frustação. 1 Uma das autoras do livro Sexualidade na escola: alternativas teórico práticas,
organizado por Julio Groppa Aquino 
Portanto, surge a necessidade do debate sobre a questão da sexualidade no campo educacional, sendo ele um dos principais responsáveis pela socialização e desenvolvimento integral da criança. Infelizmente, muitos profissionais dessa área tendem a excluir tal debate dentro das instituições de ensino, principalmente as de cunho privado e da educação infantil, que ainda funcionam de acordo com o senso comum dos responsáveis e não pelo conhecimento pedagógico de quem a conduz. Tratam o processo de descoberta e suas manifestações de forma coercitiva e impositiva, desconsiderando o impacto que será gerado na criança ao negar esse momento de interação consigo mesma.

\section{ABUSO SEXUAL INFANTIL: IMPACTO DO DESENVOLVIMENTO NEGADO}

Caracteriza-se como abuso sexual toda ação que tenha como agente um adulto, que procura satisfazer-se sexualmente pelo contato com crianças ou adolescentes. Pode se manifestar sem que haja o contato físico imediato, ao assistir a criança tomando banho, ou pedir para que ela fique nua ou/e faça gestos sexuais e sensuais, ou assista o adulto fazendo isso. Também pode ocorrer com a presença do contato, sendo ele a masturbação ou penetração.

Outras formas de abuso podem aparecer, como a exibição de conteúdo pornográfico para a criança, ou o assédio sexual. Segundo a ONG Childhood, que tem como foco a proteção de crianças e adolescentes contra abuso sexual, estima-se que apenas 10\% dos casos são denunciados no Brasil. Mas mesmo com uma porcentagem tão baixa de notificações, entre 2011 e 2017 foram registrados mais de 200 mil casos de abuso sexual infantil, dando em média 30 mil casos por ano.

Um dos fatores que dificulta o registro das denúncias é a falta de conhecimento sobre o que é o abuso e a violência sexual infantil e quando o ocorrido deve ser notificado. Outro fator que interfere no registro e na denúncia é que os abusos, 
segundo o Ministério da Mulher, da Família e Direitos Humanos, $80 \%$ dos casos acontecem dentro de casa, cometido por pais, padrastos e tios.

Outro dado que se torna muito importante é o levantamento do perfil da vítima, e, segundo o Ministério da Saúde, $51 \%$ dos casos registrados são de crianças entre 1 e 5 anos de idade. A autora Christiane Sanderson, em seu livro Abuso Sexual em Crianças (2005), aponta que os abusadores tendem a procurar crianças mais novas para cometer o abuso porque elas ainda não têm uma clara compreensão do que é certo e errado, não conseguem dizer com clareza o que acontece, dificultando a denúncia. Muitos abusadores também consideram que quanto mais nova a criança menos ela se lembrará da violência ou abuso, sendo menos prejudicial para a sua vida.

Engana-se quem acredita que os episódios de abuso não causam traumas e nem afetam o desenvolvimento infantil pelo contrário, os traumas de cunho sexual causam impactos duradouros na vida da criança, sendo levados até a fase adulta. Sanderson (2005) aponta seis áreas em que os efeitos colaterais do abuso se manifestam, sendo eles os efeitos emocionais; efeitos interpessoais; efeitos comportamentais; efeitos cognitivos; efeitos físicos e efeitos sexuais.

Esses efeitos impactam diretamente no desenvolvimento infantil. As competências adquiridas ao longo do processo passam por uma espécie de ruptura da linearidade das fases, ou seja, alcançar determinadas competências podem levar mais tempo ou podem ser adiantadas pelo estímulo indevido, pulando etapas necessárias para a integralidade desse desenvolvimento.

Portanto, todas as relações e interações que a criança passa a ter, depois do trauma, são afetadas. Sua visão e percepção de mundo começam a ser modificadas. Coloca-se em dúvida os seus valores sobre as ações que são certas ou que são erradas, em casos que o abuso acontece por meio do aliciamento, vindas de pessoas conhecidas e, até que tenham algum tipo de envol- 
vimento afetivo, no caso de os abusadores serem da família ou amigos próximos.

A interpretação da criança enquanto o que é ser um adulto, ou, qual o papel do adulto nas relações afetivas, pode ser modificada, causando dificuldade para conseguir distinguir as situações de abuso, chegando até mesmo a entender como algo natural, pois sua referência de adulto modelo foi deturpada. A construção da sua imagem e do seu papel social enquanto indivíduo pode sofrer alteração, já que seu espaço pessoal foi invadido, podendo apresentar diversas falhas em seu processo de desenvolvimento.

Ainda de acordo com a autora, "[...] as crianças são capazes de mostrar aos pais e professores uma larga variedade de impactos, cada um com um significado específico" (SANDERSON, 2005. p. 203). A mudança de comportamento repentina da criança ou de reclamações pode sinalizar a presença do abuso como, por exemplo, um extremo de isolamento ou sociabilidade nas relações sociais, percepção deturpada de si e do mundo, brincadeiras de cunho sexual muito fortes, sinais de automutilação ou falta de valorização da vida, dificuldade de aprendizagem (demonstrando retardo em seu desenvolvimento), familiaridade com barganhas e dores nas regiões das genitálias.

Apesar dos traumas desencadeados durante e após os abusos, não é possível determinar quais sequelas se manifestam de imediato ou que podem vir a aparecer ao longo dos anos, quais são mais ou menos comuns. Há uma série de fatores que determinam a profundidade desse impacto e de que forma a criança exterioriza o que aconteceu. A relação da vítima e do abusador, se foi utilizada o uso da força física e de agressões ou tática de aliciamento para conseguir consumar o ato, se foi um ato isolado ou uma sequência de abusos, qual a relação da família com o abusador e se ela é conivente com os abusos, são alguns dos fatores determinantes no processo de absorção do ocorrido pela vítima. Por isso é necessário que a discussão sobre sexualidade e violência permeiem os espaços coletivos, só 
assim as identificações de indícios poderão ser trabalhadas para que a criança consiga denunciar, ou que o adulto responsável se atente aos detalhes e consiga notificar, caso a criança ainda seja muito pequena.

\section{INSTITUIÇÃO ESCOLAR: MODIFICADORA OU PERPETUADORA?}

Depois da família, a escola é a segunda instituição social que a criança passa a ter contato, mesmo que uma parcela considerável da população nacional não tenha pleno acesso ao ensino básico. A escola é uma das responsáveis pelo processo de estímulo ao desenvolvimento nas habilidades socioemocionais, cognitiva, motora e cultural da criança e do adolescente.

A instituição acaba incorporando, muitas vezes, a função social de informar a comunidade a qual atende, ampliando o acesso sobre cultura, lazer, saúde, educação e infância. Assume, portanto, um caráter muito maior do que apenas alfabetizar e garantir o direito à aprendizagem. Pela sua importância, a instituição escolar passa a ser uma grande aliada no processo de combate ao abuso sexual infantil.

Entretanto, dentro da Base Nacional Comum Curricular (BNCC) - que é um documento que regulamenta quais são os saberes, essências, competências e habilidades que devem ser trabalhados e desenvolvidos dentro das escolas públicas e privadas, da Educação Infantil até o Ensino Médio - não é possível, por exemplo, encontrar uma diretriz que leve ao debate da educação sexual, nem mesmo pelos temas transversais.

Essa lacuna dentro da base educacional dificulta o trabalho docente para, efetivamente, trabalhar e estimular o desenvolvimento integral da criança, porque é a BNCC que norteia o Projeto Político Pedagógico, e são poucas as instituições que pensam além dos saberes necessários e propostos nesta Base para englobar temas importantes, mas que não estão explícitos e, às vezes, nem implícitos em seu regimento. Fica, então, a questão de 
como o professor pode agir dentro desse espaço sem que viole as regras institucionais, mas que seja efetivo para o cumprimento da lei que garante o direito e a proteção à infância.

O professor é a figura que está em constante contato com as crianças dentro do ambiente escolar, exercendo sua função de mediador e de agente fundamental para que a plenitude no desenvolvimento infantil seja alcançada. Portanto, é essa figura que será capaz de identificar e pontuar as mudanças de comportamento apresentadas pelos alunos, de fazer a mediação entre suas percepções e a coordenação escolar, levando as questões até a família ou órgão da Assistência Social, quando necessário.

Mas, quando o docente assume o papel de transmissor do conhecimento e enxerga o aluno como um receptor das informações, qualquer comportamento que não seja o padrão esperado dentro de sala de aula, será levado, não como uma dificuldade a ser investigada, mas como um comportamento inadmissível e que deve ser punido.

A prática docente, para que seja efetiva, deve, portanto, ser guiada pela teoria construtivista e pela afetividade entre professor-aluno. Ainda que seja o esperado, principalmente dentro de escolas que seguem essa linha, é muito difícil encontrar profissionais que consigam alinhar a sua prática ao discurso proposto pelo construtivismo, incorporando ao seu dia a dia atitudes tradicionalistas imputadas pelo behaviorismo.

Um exemplo muito comum da incoerência entre a teoria e a prática docente, na Educação Infantil, é quando a criança está passando pelo processo de descoberta do próprio corpo e os toques nas genitálias começam a ser comum, inclusive dentro da escola. Um professor construtivista entenderia que esse é um processo natural da criança, mas que por ser um novo momento ela ainda não tem distinção do porquê não é permitido tocar seu próprio corpo em determinados ambientes e situações. Cabe ao docente conversar com esse indivíduo sobre esse novo processo, 
sem que a criança se sinta constrangida ou sem que coloque o corpo e sua descoberta como algo errado.

Mas, quando há na prática docente a influência de uma educação baseada no reforço negativo e positivo, que é coercitivo, a primeira atitude do professor é a de repreender e constranger a criança que descobre seu corpo. A utilização da prática de ensino tradicional anula o entendimento e as fases de desenvolvimento proposta pela teoria construtivista, podendo, inclusive, criar uma associação da repressão sofrida no abuso e na repressão em sala de aula. A criança pequena, até a sua primeira infância, não consegue distinguir claramente a diferença das situações repressivas. Essa habilidade é adquirida somente no processo operatório-concreto.

Quando discuto e procuro sinceramente compreender outrem, comprometo-me não somente a não me contradizer, a não jogar com as palavras etc., mas ainda comprometo-me a entrar numa série indefinida de pontos de vista que não são os meus. A cooperação não é, portanto, um sistema de equilíbrio estático, como ocorre no sistema de coação. É um equilíbrio móvel [...]. (PIAGET, 1973. p. 237 apud La Taille, 1999, p. 20).

Portanto, ela vai associar e internalizar comportamentos que a faça sentir medo e impotência. Por isso é necessário que o docente não se restrinja ao que é cômodo e conhecido dentro do ambiente escolar, mas que vá além do saber teórico. Desse modo, ao exercer a práxis, conciliação entre teoria e prática, dentro da sala o professor conseguirá, além de ter uma relação mais saudável com o aluno, observar as mudanças e sinais transmitidos pela mesma.

O construtivismo dá ao docente as ferramentas necessárias para que ele consiga enxergar o processo de desenvolvimento de cada aluno, percebendo de que modo esse sujeito interage 
com o mundo e como, a partir dessas interações, demonstra e externaliza suas necessidades e suas questões interiores. É, então, a partir da mudança em sua prática que o professor conseguirá aproveitar as deixas demonstradas pelos alunos, para conversar sobre situações que podem acontecer envolvendo seu corpo. $\mathrm{O}$ conceito de regras é uma ferramenta que pode ser utilizada pelo docente, se há regras para as crianças -e adultos- respeitarem jogos, espaços e situações, também existem regras quando o assunto é seu próprio corpo e o corpo do outro, sendo o outro um colega de sala, um adulto ou uma criança mais velha. A partir do levantamento da reflexão pode ser discutido quais os tipos de toques que crianças ou adolescentes mais velhos ou adultos não são adequados, ou saber que se a forma de receber carinho as deixam desconfortáveis é porque esse carinho não está certo e não deve ser continuado.

O professor pode se deparar com duas situações quando o assunto é o abuso sexual: a primeira é quando ele já sabe do histórico de violência que envolve a criança e tem consciência de que o comportamento apresentado por ela é proveniente de um trauma. A outra, é quando o professor desconhece o abuso, mas percebe que há no comportamento da criança os traços e as características que podem indicar que há algo de errado acontecendo.

Em ambos os casos a afetividade e o pensamento construtivista são de extrema importância - no primeiro, porque é a partir dessa prática que o docente conseguirá acolher o aluno e trabalhar de forma efetiva a sua integralidade. No segundo caso, ao considerar a construção do sujeito e do seu desenvolvimento, o profissional conseguirá direcionar o seu trabalho para que possa existir um vínculo de confiança, sendo para a criança uma figura saudável de autoridade, além de observar comportamentos que indiquem o abuso.

Um dos momentos mais oportunos para observar o que acontece com a criança e que servirá para nortear rodas de conversas e atividades lúdicas que pontuem a questão do respeito, é 
a hora do brincar. É nesse período que a criança demonstrará seu entendimento, suas angústias, frustações, descobertas e como é a sua relação com as pessoas que não estão dentro do ambiente escolar, resignificando sua vivência. O brincar, principalmente na primeira infância, que a criança ainda não consegue dizer com clareza o que aconteceu, é um aliado da prática docente, não só para que o professor observe o aluno mais agressivo, mas para que também consiga perceber alunos muito apáticos, que se isolam e apresentam uma baixa autoestima.

\section{CONSIDERAÇÕES FINAIS}

O presente trabalho teve como finalidade discutir o problema de relação entre desenvolvimento infantil e o desenvolvimento sexual da criança, e de que modo trabalhá-los separadamente dentro do ambiente escolar impacta negativamente o processo de desenvolvimento integral infantil. A descoberta de seu corpo, em sua totalidade, dá a criança a possibilidade de se enxergar enquanto um sujeito que interage com o mundo, percebendo como o mundo também interage com ela, e, acima de tudo, sendo ela própria seu objeto de descoberta. O professor é a figura que irá mediar esse processo de conquista de si e de novos territórios que despertam o interesse da criança, sendo capaz de intervir nos momentos que o individuo apresentar dificuldades para desenvolver novas habilidades ou competências. Inclusive, sendo capaz de identificar comportamentos peculiares na criança, desde um indício de transtorno ou, até mesmo, alguma violência que a criança está passando.

Surge, portanto, outra problemática apontada e discutida ao longo do texto - de que modo a prática docente construída dentro da sala de aula pode auxiliar ou dificultar o processo de identificação e denúncia de crianças vítimas de abuso sexual. Este trabalho propõe uma reflexão sobre a abordagem docente dentro do ambiente escolar; é a partir dela que pode acontecer a dinâmica de naturalização do abuso, quando a ação do professor 
se assemelha à do abusador, por meio do tom coercitivo e intimidador, reforçando a postura de docilidade e desencorajando o questionamento da situação que está vivenciando. Ou, quando há o estímulo para que a criança se desenvolva integralmente, ensinando-a sobre seu corpo e sobre o aspecto moral (certo/ errado) do abuso, compreendendo os sinais dados a partir da linguagem infantil de que há um problema em seu processo de interação com o mundo.

Desse modo, pensar uma prática docente a partir da abordagem tradicional é ir contra o processo de desenvolvimento da criança e contra o seu direito à aprendizagem plena. Isenta o professor da responsabilidade de enxergar o aluno como um indivíduo, entendendo-o como um número que deve ser moldado dentro da normatividade, e não como sujeito das suas próprias ações e pensamentos. Desumaniza-se, portanto, o aluno, pois, ao negar-lhe seu desenvolvimento, nega-se, também, os seus direitos, já que este é visto apenas como um instrumento receptor do conhecimento. Portanto, conclui-se que, a prática docente construtivista é uma aliada no processo de identificação do abuso sexual infantil, enquanto a prática tradicional perpetua a relação de poder do adulto sobre a criança.

Entretanto, ainda que a prática docente possa auxiliar no processo de identificação e de denúncia dos casos de abuso sexual, o índice nacional desse tipo de violência ainda é muito alarmante. Apenas a mudança dentro do ambiente escolar não é capaz de modificar um problema de caráter histórico-social, mas é o primeiro passo para conscientizar as famílias sobre como o abuso pode acontecer, e de ser a voz das crianças que ainda não conseguem apontar o abuso, seja pela pouca idade ou pela profundidade do trauma causado.

\section{REFERÊNCIAS}

AQUINO, Julio Groppa (org). Sexualidade na Escola: Alternativas Te'rocias e Práticas. São Paulo: Summus, 1997. 
BRASIL. "Base Nacional Comum.” Ministério da Educação. 2017. http:// basenacionalcomum.mec.gov.br/images/BNCC_EI_EF_110518_versaofinal_site. pdf (acesso em 30 de maio de 2020).

BRASIL. Ministério da Mulher, Família e Direitos Humanos. s.d. https:// www.gov.br/mdh/pt-br/centrais-de-conteudo/videos/maio-laranja-ministeriodivulga-dados-de-violencia-sexual-contra-criancas-e-adolescentes (acesso em 03 de Junho de 2020).

CHIDHOOD. Chidhood Bbrasil. 14 de Agosto de 2019. https:/ / www.childhood. org.br/a-violencia-sexual-infantil-no-brasil (acesso em 15 de Outubro de 2019).

KUPFER, M. Cc. Freud e a Educação: O Mestre o do Impossível. $3^{\text {a }}$ ed. São Paulo: Editora Scipione, 1997.

LA TAILLE, Y et al. Piaget, Vygotsky, Wallon: teorias psicogenéticas em discussão. São Paulo: Summus, 1992.

SANDERSON, C. Abuso Sexual em Crianças. Tradução de Frank de Oliveira. São Paulo: M. Books do Brasil Editora, 2005. 